\title{
La experiencia del teatro digital durante la pandemia por la COVID-19 en Lima
}

\section{The Digital Theater Experience During the COVID-19 Pandemic in Lima}

Es actriz, directora y educadora, con 19 años de experiencia artística. Es máster en Docencia para la Educación Superior por la Universidad Andrés Bello de Chile (2020), egresada de la Facultad de Educación de la Pontifica Universidad Católica del Perú (2008) y egresada de la Escuela de Teatro (2001). Actualmente, se desempeña como directora de Radioteatro UPC para UPC Cultural y como profesora de Entrenamiento Vocal en la carrera de Artes Escénicas de la Universidad Peruana de Ciencias Aplicadas (UPC). En el año 2021, participó en el libro digital Vivências de mulheres no tempo e espaço da pandemia de Covid-19, publicado por la editora CRV, con el artículo «SEGUIR CREANDO: casos de artistas escénicas creando durante el confinamiento estricto por la crisis del Covid-19 en Lima». 



\title{
La experiencia del teatro digital durante la pandemia por la COVID-19 en Lima
}

\section{The Digital Theater Experience During the CoVID-19 Pandemic in Lima}

\author{
Sofía Magaly Rebata Delgado \\ Universidad Peruana de Ciencias Aplicadas, Perú \\ sofiarrebata@hotmail.com, rebata.sm@pucp.edu.pe \\ (https://orcid.org/o00o-0002-9821-1687) \\ Recibido: 31-05-2021 / Aceptado: 23-09-2021 \\ https://doi.org/10.1880o/conexion.202102.002
}

\section{PALABRAS CLAVE / KEYWORDS}

Teatro peruano, teatro digital, convivio, tecnovivio, pandemia, COVID-19 / Peruvian theater, digital theater, gathering, techno-gathering, pandemic, COVID-19

\section{RESUMEN}

La pandemia por la COVID-19 trastornó la convivencia entre humanos y la alternativa frente al distanciamiento social ha sido mantener los vínculos comunicacionales mediante la tecnología. Con ello, se afectó el convivio - en términos de Jorge Dubatti (2015) - , un rasgo sustancial de la identidad del teatro, y se optó por el tecnovivio a través del teatro digital. La definición de teatro digital y la relación -mediada por la tecnología- entre los artistas escénicos y las audiencias se encuentran en construcción, así como su gestión sostenible. Con el objetivo de analizar la experiencia local, se ha revisado la situación del teatro peruano - antes y durante la pandemia- y se han realizado entrevistas semiestructuradas a tres creadores escénicos, quienes tuvieron temporadas en Lima en medio de la crisis sanitaria. A través de los datos cualitativos recogidos, se identifican las fortalezas, las debilidades y los alcances a futuro de este formato.

\section{ABSTRACT}

The COVID-19 pandemic disrupted human coexistence and the alternative to social distancing has been to maintain communication links through technology. With this, gathering-in Jorge Dubatti's terms (2015) - , a substantial feature of the identity of theater, was affected, and the choice was made for techno-gathering through digital theater. The definition of digital theater and the relationship-mediated by technology-between scenic artists and audiences are under construction and sustainable management. To analyze the local 
experience, we have reviewed the situation of Peruvian theater-before and during the pandemic-and conducted semi-structured interviews with three-stage creators from Lima, who had seasons during the health crisis. Through the qualitative data collected, the strengths, weaknesses, and future scope of this format are identified.

\section{La experiencia del teatro digital durante la pandemia por la COVID-19 en Lima}

Tomar conciencia de que entre convivio y tecnovivio no hay sustitución superadora, sino alteridad, tensión y cruce. $Y$ es importante hacer entender, a través de esta política, que ir perdiendo la cultura del convivio es perder uno de los tesoros más incalculables de la humanidad.

Jorge Dubatti (2015, p. 50)

La humanidad está lidiando con una crisis sanitaria debido a la pandemia generada por la COVID-19. Los cuidados básicos para evitar el contagio de esta enfermedad aún sin tratamiento efectivo son el lavado de manos, el uso de mascarilla y el distanciamiento social. Además, en la mayoría de los países, el confinamiento estricto es la principal medida para controlar los contagios cuando estos presentan altos incrementos.

El Perú está atravesando por esta situación desde el 6 marzo de 2020, cuando se rentena estricta el 16 de ese mes. Desde entonces, y hasta junio de 2021, los centros culturales y los teatros permanecieron cerrados; recién a partir de ese mes, algunos empezaron a abrir con aforo restringido. Esta situación ha generado una profunda crisis para el sector. Frente a estas circunstancias, los artistas escénicos peruanos han sorteado las dificultades primero de manera independiente y luego con la limitada ayuda del Estado.

La posibilidad de seguir creando y de mantener el contacto con el público se trasladó al espacio virtual, donde se difundió el teatro digital, principalmente emitido desde la plataforma Zoom. Sin embargo, la definición de qué es el teatro digital -considerando que el término es usado de diferentes maneras desde 1995 , aproximadamente- se encuentra en construcción, así como la relación, mediada por la tecnología, entre los artistas y las audiencias, y la gestión sostenible en este formato.

Con el fin de conocer de manera cercana la experiencia de artistas escénicos en Lima y sus apuestas creativas durante el contexto de la pandemia, se realizaron entrevistas cualitativas con preguntas abiertas y una guía semiestructurada a Carol Hernández, Gabriel de la Cruz y Diana Daf Collazos. A través de los datos recogidos, se hace un balance de las fortalezas y debilidades del teatro digital y del camino por seguir en este formato, y se intentan dilucidar las repercusiones 
que tendrá en el regreso a la convivencia presencial.

\section{Revisión situacional del teatro peruano}

El teatro peruano se encontraba en crisis antes de la pandemia; las políticas culturales eran escasas y, por ello, la promoción estatal era mínima y dependía de las autoridades de turno. Además, solo considerando las cifras de las obras que venden y distribuyen sus entradas a través de plataformas, con puntos de venta en supermercados o en línea, el teatro no contaba con cifras alentadoras de audiencias. Por otro lado, en un país de más de 32 millones y medio de personas, los teatros, centros culturales y salas alternativas están concentradas en Lima. Existen escasas salas de teatro en provincias y, de hecho, estas están ubicadas en las ciudades capitales más grandes. En el Perú, según afirma Rodríguez, de los 225 teatros y auditorios, «el $80 \%$ contaba con un aforo promedio de 200 personas y el $20 \%$ permitía la entrada de 500 espectadores aproximadamente» (2020, párr. 2). Más aún, en Lima metropolitana, dichos espacios se encuentran aglutinados en unos cuantos distritos. Esta situación representaba un obstáculo para las personas, quienes, para asistir a las funciones, debían cruzar largas distancias y sortear el tráfico, que es también un grave problema en la capital.

Los grupos y elencos de teatro profesionales y semiprofesionales - los que cuentan con apoyo de instituciones y los independientes- acceden a un limitado patrocinio por parte de la empresa privada. Las obras se financian con inversión de los propios artistas, quienes con mucha dificultad alcanzan a recuperar lo invertido o llegan a ganar. Los artistas escénicos solventan sus ingresos personales trabajando en áreas profesionales como la docencia, la televisión, la radio, la publicidad; en eventos para empresas privadas; etcétera. Estos trabajos suelen realizarse de manera independiente y una minoría de artistas escénicos cuenta con empleos o contratos laborales en empresas formales.

En nuestro país, «la carrera de artes escénicas ingresó al nivel de educación superior en el año 2009» (Rebata Delgado, 2020, p. 21). Al presente, dos escuelas superiores del sector público - una ubicada en Lima y otra en Trujillo, ambas con rango universitario- $-\mathrm{y}$ tres universidades privadas con sede en la capital forman profesionales en artes escénicas. Con ello, la oferta profesional y la producción de montajes crecieron, pero no aumentaron los espacios para albergarlas.

Las artes escénicas en el Perú se encontraban en una situación mayormente informal y precaria; por ello, afrontar las consecuencias de la pandemia fue una tarea compleja y retadora. Una de las medidas que se tomó antes de ingresar al confinamiento estricto fue limitar el aforo de los espacios. Así, el Festival de Artes Escénicas de Lima (FAEL) tuvo que can- 
celar su programación y, junto con este, todas las obras en temporada. Esto significó devolver las entradas, incluyendo las obras que estaban por ser estrenadas. De acuerdo con la Asociación Playbill, «se cancelaron 453 temporadas y se devolvieron 15025 entradas», lo que significó una pérdida de «S/ 4.5 millones» (Cubas, 2020, párr. 3).

Frente a esta situación, los artistas escénicos demandaron que el Ministerio de Cultura otorgue el apoyo necesario a las y los trabajadores de la cultura -entre ellos, los artistas escénicos-, pero este sector no contaba con un empadronamiento para canalizarlo. La situación era muy crítica: sin la posibilidad de generar ingresos, los artistas asumían la crisis sanitaria en circunstancias lamentables. El 21 de mayo de 2020, durante el entonces Gobierno de Martín Vizcarra, se publicó el Decreto de Urgencia ${ }^{\circ}$ 058-2020 (2020), que otorgó una partida presupuestal de S/ 50 millones destinados para el desarrollo y la promoción de las artes e industrias culturales. Poco después, y debido a un presunto caso de contratación ilegal, la ministra de Cultura, Sonia Guillén, renunció a su cargo el 30 de mayo y asumió el puesto el ministro Alejandro Neyra. El 11 de junio se publicaron los lineamientos para ejecutar el decreto de urgencia (Rebata Delgado, 2021, p. 259). En este marco, artistas y gestores de espacios escénicos postularon para acceder a estos recursos y para poder aliviar así la carga económica.
A fines del año 2020, el Gobierno flexibilizó algunas medidas sanitarias sobre la base de la disminución de los contagios, y permitió que los teatros abran en un 40 $\%$ de su capacidad; sin embargo, ninguna sala lo hizo. En noviembre de ese año, hubo una convulsión política debido a que, el 9 de noviembre, el Congreso de la República vacó al presidente Martín Vizcarra, lo que desencadenó movilizaciones masivas de protesta en todo el país.

Recién a fines del verano de 2021, el Auditorio Miraflores y el teatro de la Alianza Francesa, también ubicado en el distrito de Miraflores, abrieron una boletería virtual para obras presenciales. No obstante, unas semanas después el Gobierno cambió el aforo solo al $20 \%$ del habitual, debido a que una agresiva segunda ola de la COVID-19 superaba en muertes a la primera. El Estado decidió, entonces, actualizar las medidas sanitarias cada quince días, situación insostenible para planificar una programación en las salas.

En Europa y en Norteamérica, la pandemia había llegado dos meses antes. A través de su experiencia, había referentes de la adaptación a las clases virtuales en las carreras de artes, así como obras de teatro transmitidas en línea o grabadas. En el Perú, durante el primer mes de confinamiento, las redes sociales se llenaron de conversatorios para reflexionar sobre el futuro del teatro. Luego, se estrenó la primera obra de teatro en línea, Fantasma - escrita y dirigida por Mariana de Al- 
thaus-, basada en la obra de microteatro La peluca y adaptada a la crisis sanitaria; contó con dos funciones: el 29 y el 30 de mayo (Japa Rojas, 2020). Días después, el teatro La Plaza, uno de los más grandes y de mejor gestión comercial en Lima, estrenó Junta extraordinaria, creación de Alejandro Clavier, Chela de Ferrari, Luis Alberto León y Claudia Tangoa. La obra online relató la reunión, mediante videollamada, de un grupo de vecinos para coordinar las medidas de cuidado frente al coronavirus (Denegri, 2020). A estas dos propuestas les siguieron varias obras más, entre remontajes, adaptaciones y creaciones originales.

De esta manera, empezó a expandirse la producción de teatro online, que utilizó principalmente la plataforma Zoom. La mayoría de estas obras eran realizadas por artistas jóvenes de Lima, Trujillo, Arequipa y otras ciudades, quienes encontraron una oportunidad para producir teatro a un costo significativamente bajo, es decir, sin tener que cubrir el costo de una sala de teatro, con pequeñas inversiones en escenografía, utilería, vestuario e iluminación y con la difusión centrada en las redes sociales y la prensa digital. Esto conllevó también la reducción en el precio de las entradas, no solo por la disminución del costo que significa el ingreso a las plataformas virtuales, sino también por el hecho de que, con una sola conexión, más de una persona podría disfrutar la obra. La posibilidad de ver obras de teatro sin trasladarse a un lugar físico determinado para ese fin permite también que públicos de diferentes ciudades y países puedan acceder a estos productos sin mayores dificultades. Esto, en concreto, es propicio para democratizar la producción y el acceso, al menos entre los creadores y espectadores que contaban con conexión a internet.

A lo largo de la prolongada crisis sanitaria, el teatro que se transmite a través de plataformas virtuales ha recibido distintos nombres: teatro virtual, digital, online, híbrido, entre otros, y ha atravesado diversos experimentos actorales, de dirección y, sobre todo, técnicos, con obras trasmitidas en directo o grabadas completa o parcialmente. El joven actor Sergio Baltazar comentó en una entrevista que, con el propósito de mantener las características del teatro en vivo, graba su obra con tres cámaras en simultáneo y sin edición («Jóvenes actores presentarán obra», 2021). Los artistas y trabajadores escénicos buscan, en este nuevo formato, seguir creando hasta que termine la pandemia; sin embargo, este formato desarrolla su propio camino como un nuevo lenguaje y comienza a alimentar el imaginario de la creación a medida. Por ejemplo, el teatro La Plaza, en abril de 2021 estrenó la temporada de No voy a salir, obra online en la que parte del elenco está de manera presencial en el teatro y los otros actores, así como el público, participan de manera virtual, propuesta difícil de imaginar antes de la pandemia. 


\section{Experiencia de teatro grabado y televisado en el Perú}

El historial de esta concepción se ha dado de formas diversas en el Perú. En 1997, el auto sacramental de gran formato El gran teatro del mundo, de Pedro Calderón de la Barca, dirigido por Luis Peirano y producido por la Pontificia Universidad Católica del Perú, tuvo una breve temporada en espacio público y luego fue trasladada al formato audiovisual. Se filmó con varias cámaras, y fue editada y transmitida en televisión de señal abierta a través del canal del Estado.

También hubo otra experiencia entre los años 2002 y 2008: el programa de televisión Teatro desde el teatro. Era grabado con público en vivo y se transmitía en un canal de señal abierta y en horario estelar. Era dirigido, y muchas veces actuado, por Ricky Tosso.

\section{El teatro digital}

¿El confinamiento dado para controlar la pandemia adelantó el futuro? Sí, en el sentido de que creó la necesidad de conocer las posibilidades de comunicación que permiten las tecnologías existentes. La pandemia adelantó la masificación del uso de estas tecnologías a nivel global en la población que tiene acceso a ellas.

De igual modo, los artistas con acceso a internet, y al menos con el manejo bá- online, siguieron creando y encontrándose con el público de manera indirecta. El aquí y ahora del teatro presencial se había transformado solo en el ahora al ser transmitido de manera sincrónica; sin embargo, con la mediación tecnológica, la reacción del público no dialoga en tiempo real con la obra. No existe el convivio.

El teatro transmitido por Zoom, en la mayoría de los casos, era diferente al audiovisual, por ser sincrónico, y de una hechura artesanal. La sincronicidad era difícil de sostener, porque tener una buena conexión a internet no garantizaba que no falle en algún momento, o que uno de los espectadores tenga problemas con ello y vea la obra distorsionada. Además, es en parte artesanal, no solo por las limitaciones para actuar desde casa, sino por el mínimo o nulo manejo del lenguaje audiovisual por parte de los artistas escénicos. Entonces, ¿por qué un espectador acostumbrado a consumir productos audiovisuales y a la inmediatez de las redes sociales asistiría a la transmisión de una experiencia cercana al teatro? La alternativa de hacer teatro por internet era contradictoria y dividió las opiniones de los artistas escénicos. Era necesario reflexionar sobre ello y revisar los principios del teatro, como sucedió con la aparición del cine y de la televisión, y quizá buscar un nombre nuevo para este formato, que comienza a tener su propio discurso ante la prolongación de la emergencia sanitaria. 
Revisemos los antecedentes. Los avances tecnológicos son herramientas que permiten perfeccionar el modo de vida de los humanos y se han incorporado al arte a lo largo del tiempo. El mundo digital, en específico, mediatiza nuestras formas de producción y comunicación (López Pellisa, 2013, p. 24), y algunos de sus recursos ya se introducían en el ámbito artístico desde hace varias décadas. En el escenario presencial, por ejemplo, Minafro Spinelli (2015) apunta que cientos de artistas alrededor del mundo emplean en sus obras una estética híbrida, conjugando el lenguaje escénico y las posibilidades del lenguaje multimedia.

En el Perú, el Grupo Íntegro, dirigido por Oscar Naters y Ana Zavala, con más de 37 años de experiencia, tiene como sello creativo el ser un grupo que «trasgrede las típicas fronteras de los lenguajes artísticos para expresarse a través de una composición humana en la que todos los recursos se convierten en signos de un lenguaje multidimensional y experiencial» (Gran Teatro Nacional, 2019, párr. 3). Este grupo, reconocido a escala nacional e internacional, es un referente del diálogo íntimo con las narrativas que permite el uso de la tecnología.

Entre las nuevas tecnologías que se emplean en el teatro multimedia, se encuen- tran el tracking video, la realidad aumentada y el mapping, cuya definición y campo de aplicación se encuentra aún en construcción (Minafro Spinelli, 2015, p. 128). No obstante, en este tipo de espectáculos, sigue presente la convivencia única que el teatro permite: compartir el mismo aquí - espacio inmediato- y el mismo ahora -tiempo inmediato - entre los actores y el público, así como el allá y entonces, entre el texto -en su acepción más amplia-y el lugar de la ficción. De igual manera, permite la interacción entre la propuesta y la interpretación sincrónica que cada persona del público le da al hecho escénico.

En palabras de Jorge Dubatti, crítico, teórico e historiador, «el teatro es una reunión territorial de cuerpos», reunión que se da «sin intermediación tecnológica» (2015, p. 45). En el mismo espacio y tiempo se reúnen los artistas, los técnicos y los espectadores para compartir un acontecimiento efímero (Dubatti, 2011, pp. 35-36) donde mirar, percibir, pensar e inteligir (Dubatti, 2016, p. 19), y es esto lo que lo diferencia del cine, la televisión y la radio (Dubatti, 2011, p. 35). Lo opuesto al convivio es el tecnovivio, en el que «no hay sustitución superadora, sino alteridad, tensión y cruce» (Dubatti, 2015, p. 50).

Existe una amplia experiencia en obras de teatro y performances ${ }^{1}$ que incluyen el

\footnotetext{
${ }^{1} \mathrm{Al}$ denominar una obra escénica o acción corporal con el término performance, se alude a las disposiciones formales del arte de la acción, arte vivencial que anhela tomar distancia del carácter representacional con los argumentos de la obra. Esta última característica no solo se hace efectiva en las ideas del artista cuando crea una obra, sino también en los significados que el público receptor le puede dar (Villalobos Herrera, 2017).
} 
uso de lenguaje híbrido o de multimedia, pero ello no implica romper el convivio. Dentro del universo de las artes vivas, este artículo se centra en la experiencia específica del arte teatral o teatro.

La práctica del teatro digital transmitido sincrónicamente por internet no permite la interacción en el mismo tiempo y espacio real entre artistas y espectadores, incluso con la participación de estos a través de los chats, ya que las reacciones son emocionales e instantáneas y el escribir implica un acto secundario. Además, al no compartir un mismo espacio físico, no se puede asegurar una inmersión en la ficción propuesta; es decir, no se puede asegurar que la intencionalidad del artista llegue al espectador de la manera en que esta se compone para el teatro. Sin embargo, en situaciones, como la actual, en que el único medio de convivencia humana es el mediado por el internet, ¿es posible llamar teatro al que es trasmitido online?

En la otra orilla, y varios años antes de la pandemia, existía una forma de hacer teatro a la que también denominaron digital, pero con diferentes características. La compañía La Fura dels Baus, en 1995, hizo la presentación de una obra que ocurría en simultáneo en dos teatros ubicados en distintas ciudades de Europa: lo que sucedía en una sala era proyectado en la otra vía internet (Antón, 1995). Es decir, la obra proponía en una misma experiencia una parte convivial, donde artistas y espectadores compartían el tiempo y espacio inmediato, y otra tecnovivial, donde artistas y espectadores solo compartían el mismo tiempo.

Igualmente, se le llama teatro digital al hecho de grabar teatro presencial con gran despliegue tecnológico y reinterpretar su contenido a través del lenguaje audiovisual; con ello, se crea un producto nuevo con otras posibilidades de distribución. Nos referimos, por ejemplo, a las funciones de stand up o a las grabaciones de obras de teatro que se combinan con un tratamiento documental, disponibles en Netflix u otras plataformas de streaming especializadas en ofrecer teatro digital o grabado con gran calidad técnica, como Alltheater, Teatrix, The Digital Theatre of London y Teatron.

\section{La Fura dels Baus: diversas concepciones del teatro digital}

La Fura dels Baus es una compañía de teatro catalana que desarrolla obras en gran formato y es un ícono de la investigación e innovación del teatro como espectáculo. Esta compañía, en 1995, estrenó la obra Working in progress, pionera del teatro digital, al que definieron como «la fricción entre las artes escénicas a través de Internet» (Ley, 1997, párr. 1).

Esta obra sucedía en dos teatros diferentes, uno en Cardiff (Gales) y otro en Barcelona (España); se presentaba con dos compañías, Brith Gof y La Fura dels Baus; 
y contaba con público presencial en cada recinto. Las partes de esta obra se unificaban al transmitirse, vía internet, en cada una de las salas en simultáneo. En ese tiempo, La Fura dels Baus publicó El manifiesto binario, en el que afirmaban que:

El teatro digital se refiere a un lenguaje binario que conecta lo orgánico con lo inorgánico, lo material con lo virtual, el actor de carne y hueso con el avatar, la audiencia presente con los internautas, el escenario físico con el ciberespacio ${ }^{2}$.

La obra siguió presentándose un par de años más y luego siguieron otros proyectos en los que el lenguaje multimedia estuvo presente, como en la obra $\varnothing B S$ - diminutivo de obsesión- (La Fura dels Baus, 200o); ahí, a través del lenguaje escénico-tecnológico, los actores, que por momentos están en tiempos y lugares diferentes, se mezclan con «imágenes tridimensionales proyectadas en pantallas móviles» y se entregan a una «fascinación por lo visual» (Cañas-Restrepo, 2005, p. 147).

En 2020, en medio del confinamiento por la pandemia, La Fura dels Baus creó la obra La maldición de la corona, dirigida por Pep Gatell y basada en Macbeth de William Shakespeare, y transmitida solo por streaming. La periodista Vidales reseña para el diario El País la experiencia de esta obra de teatro digital: «Es un complejo entramado de escenas en directo, vídeos pregrabados, imágenes diseñadas por ordenador y música que se sucede a buen ritmo y que juega visualmente con elementos icónicos de la trama de Shakespeare» (2020, párr. 4).

El teatro digital es un formato que se masificó ante la necesidad de seguir creando en pandemia; para la compañía La Fura dels Baus, en cambio, es un formato con el que experimenta desde hace 25 años. Su investigación ha transitado por combinar lo convivial con lo tecnovivial, así como por ampliar los límites del lenguaje escénico y audiovisual en el teatro presencial. Durante la pandemia, ha trasladado esta experiencia al teatro meramente digital. Para Pep Gatell, uno de los directores de la compañía, se ha dado «un cambio de paradigma» y ahora «lo virtual se mezclará con lo presencial y el teatro será más híbrido» (Vidales, 2020, párr. 9).

\section{Teatrix o el teatro en lenguaje audiovisual}

En el año 2015, la psicóloga y empresaria Mirta Romay creó la plataforma de teatro digital Teatrix, donde se ofrecen obras de teatro filmadas y editadas especialmente para enfatizar la dramaturgia de la obra. La dirección de la obra y la de las cámaras dialogan para guiar el ojo del espectador respetando la intención del montaje y re-

${ }^{2}$ Una versión de El manifiesto binario traducido al portugués puede verse en Marques (2013). 
saltando detalles del trabajo actoral. Es decir, la obra, creada de manera artesanal, a diferencia de una película, es filmada como «hecho artístico» (RASL DASL Bs As, 2021).

Por el lado económico, Romay recalca, de forma crítica, que el costo para la realización de una obra de teatro es alto y que se suele planificar recuperar esa inversión y generar ganancias en solo los tres meses que dura la temporada. En cambio -sigue Romay-, el teatro filmado permite incrementar los réditos económicos y, por ende, ayudar con la sostenibilidad de la creación. Inicialmente, encontró resistencia frente a este formato por parte de los artistas y productores, pero estaba segura de que sería cuestión de tiempo para que se familiaricen con plataformas «OTT (over the top)» (Zucchi, 2021, párr. 17).

Ella también sostiene que el teatro filmado no es el reemplazo del teatro presencial, sino una evolución en los medios: «El teatro es el teatro y va a seguir siendo así y por suerte para Teatrix; tiene que generarse mucho teatro. $Y$ puede ser que por esta vía vayan más espectadores» (Tmt comunica, 2018). Teatrix propone una nueva forma de consumo, distinta a cualquier otro producto audiovisual y que atiende las necesidades de un sector del mercado. En cifras, Teatrix era una empresa rentable antes de la pandemia, según lo reportaba Infobae a inicios de 2019: «Teatrix cuenta con más de 7.000 sual de \$250) y 100 títulos, entre nacionales e internacionales» (D'Andraia, 2019, párr. 5), además de tener un convenio con Broadway HD. La pandemia permitió que esta plataforma tenga un crecimiento exponencial del $300 \%$. (Zucchi, 2021, párr. 2) con un costo actual de $\$ 7.99$ al mes. Sobre la base de las cifras, es innegable que existe un mercado interesado en este producto híbrido, en el que el lenguaje escénico es reinterpretado por el audiovisual.

El teatro transmitido de manera sincrónica vía online es lo que La Fura dels Baus denominaba teatro digital, aunque, con el correr de los meses, muchos artistas optaron también por grabar sus obras -bajo diversas condiciones técnicas- $y$, con ello, asegurar la experiencia del espectador; así, se ubican más cerca de la definición de teatro digital dada por las plataformas on demand. En este tiempo de transición, la configuración de lo que ha sucedido con el teatro en la pandemia aún está en desarrollo. Quizá es útil mantenerse flexible ante lo que ocurre y tomar en cuenta la reflexión de Teresa López Pellisa, quien indica que el hecho escénico, con características artísticas y estéticas, tomado como tal por creadores y espectadores, es parte del arte teatral, aunque:

se hace necesario acuñar nuevos términos para las producciones mediadas que generan productos desconocidos que se asemejan al teatro, pero que no tenemos por qué considerar funciones teatrales, ya que tal y como 
decía Wittgensttein «los límites de mi mundo son los límites de mi lenguaje» (López Pellisa, 2013, p. 37).

Por lo pronto, y en el tramo que queda por recorrer para superar la pandemia, es necesario que la praxis tenga su propio proceso y que este sea observado de manera crítica para el análisis y la reflexión posterior. Este tiempo de pausa del teatro ha permitido problematizar el hecho escénico, revisar sus fundamentos y revalorar su rol en la sociedad.

\section{Experiencias del teatro digital en el Lima}

Así pues, a fin de comprender con detalle y cercanía la experiencia peruana en el teatro digital, específicamente en la limeña, se revisará la travesía que han realizado tres artistas escénicos y su observación crítica frente a esta. Ellos son Carol Hernández, comunicadora, docente y actriz especializada en improvisación, que en 2015 creó el formato y método de enseñanza de improvisación testimonial; Gabriel de la Cruz, actor y director de teatro y teatro testimonial, fundador y presidente de la ONG Presente, experto en diversidad e inclusión; y Diana Daf -Diana Collazos-, artista interdisciplinaria, directora audiovisual y gestora cultural, que desde 2007 es socia fundadora de la asociación cultural Elgalpon.espacio.

\section{El teatro testimonial en el formato digital}

Carol Hernández, en el momento en que declararon el estado de emergencia, ensayaba una obra que era una mezcla de improvisación testimonial y clown. El viernes 13 de marzo había realizado la sesión de fotos para diseñar las piezas gráficas; dos días después, el entonces presidente Martín Vizcarra ${ }^{3}$ daba un mensaje a la nación en el que declaraba la cuarentena estricta. En unos cuantos días, Carol entendió que debía cambiar la forma de trabajar el teatro durante el tiempo que durara la pandemia y reunió a sus alumnos de impro testimonial para generar un espacio de contención frente a la incertidumbre. Hizo dos laboratorios gratuitos, lo que le permitió, a su vez, probar las posibilidades del Zoom, tanto para enseñar como para crear. También, junto a dos colegas, organizaron conversatorios para reflexionar sobre lo que estaba ocurriendo. Un mes después, Carol contaba con herramientas suficientes para dirigir en este nuevo formato. Así nacieron los montajes Fin de impro y El mundo iba. En cita para esta investigación, ella menciona que «para crear en teatro virtual, más que reemplazar o adaptar el teatro presencial, es necesario redefinir». Así, analizó los ejercicios y disparadores que empleaba al dirigir a sus actores para extraer de ellos los principios y objetivos que persiguen y, sobre la base de eso, los

\footnotetext{
${ }^{3}$ Su mandato presidencial fue del 23 de marzo de 2018 al 9 de noviembre de 2020.
} 
remodeló. Ella consideró que debía dejar de dictar temporalmente un curso que enseñaba en la universidad por respeto a los principios de trabajo, al verse limitada la posibilidad de crear de manera colectiva con interacción entre los cuerpos en un mismo espacio. En general, no adaptó proyectos escénicos ni cursos anteriores a la crisis sanitaria, sino que creó nuevos. Como señaló en comunicación para esta investigación: «Si es virtual, necesita un nuevo nombre, porque es otro tipo de escenario».

Le sorprendió la profundidad a la que se puede llegar con el teatro testimonial en el formato virtual, debido al estado de apertura a la vulnerabilidad en el que se encuentran los intérpretes, tanto por la situación frente a la pandemia como por el hecho de que trabajan desde un espacio que implica exponer parte de su intimidad, por estar en sus propias casas y frente a sus cohabitantes. Adicionalmente, en un mismo grupo de trabajo tuvo la posibilidad de contar con personas en diferentes partes del Perú y del mundo, lo que le permitió generar lazos de empatía desde las diferencias y similitudes. Incluso, sus alumnos de provincia señalaban que la pandemia resultaba ser un gran beneficio para ellos, porque les permitía trabajar con profesionales que se encontraban en Lima. Todos estos elementos terminaban siendo insumos para la creación.

En referencia a la estética, Hernández momentos actuados se realizan mirando al otro y las partes en las que se dan los testimonios se actúan mirando a la cámara y cerrando el primer plano. Para componer en este formato, llevó una capacitación con la improvisadora y comunicadora audiovisual colombiana Marisol Correa, en la que revisó planos, encuadres, valor de plano y cómo el plano puede hablar de una emoción.

Realizó dos montajes de improvisación de largo formato con un elenco internacional: El mundo iba, bajo su dirección; y Mínimas, donde actuaba. Con estas obras llevó a cabo seis temporadas de un mes cada una. En total, Carol participó como directora y actriz en ocho obras durante el año 2020. Las funciones se realizaron los sábados y domingos a las tres de la tarde en el Perú, en consideración con la diferencia horaria de quienes participaban desde España. El horario funcionó en buena parte porque en el Perú no había competencia con otras temporadas que tuviesen función a partir de las ocho de la noche, como usualmente se hacía en el teatro presencial.

Crearon un espacio para interactuar con el público en el after de cada obra, que consistía en que el equipo artístico conversara con los espectadores después de la función. Los afters, según menciona Hernández, se diseñaban para que el público se sintiera cómodo de participar. Por ejemplo, se ponía música festiva, un moderador planteaba preguntas para los 
actores y el público era invitado a participar libremente y a interactuar con los actores. Otro espacio para la interacción con el público era la activación del chat; cuando las características de la obra lo permitían, se recibían las reacciones de manera inmediata.

Actualmente, Carol sigue con proyectos para teatro digital. Ella proyecta que el elemento virtual se va a emplear más en lo presencial, incluyendo la posibilidad de trabajar con elencos internacionales. Afirma, por último, que el teatro después de la pandemia necesariamente tendrá cambios a nivel técnico, actoral y artístico.

\section{Versionar y crear en formato digital}

Gabriel de la Cruz estaba en Lima cuando declararon el confinamiento estricto. En ese momento, se encontraba en medio del proceso creativo de una obra que dirigía y producía. Este era un proyecto de la ONG Presente ${ }^{4}$, liderada también por él, en el que se había invertido en una sesión de fotos y en la elaboración de la carpeta para la búsqueda de auspiciadores. Al inicio, esperaba que el confinamiento se levantara en un mes, pero, al ver que no era así, decidió, junto con la sala de teatro, posponer la obra para el siguiente año. Gabriel decidió vivir unos meses en el campo.
Poco después, el teatro La Plaza lo invitó a hacer el remontaje -en versión de teatro digital- de la obra Congreso, que pasó a llamarse Congrezoom. Era una obra unipersonal, en clave de humor, en la que Ernesto Pimentel, actor y conocido conductor de televisión, representaba a una presidenta del Congreso peruano y se dirigía al público como si ellos representaran el pleno del Congreso. En la versión presencial, la obra tenía una estructura definida con gags ${ }^{5}$ marcados, y se apoyaba en la improvisación del actor y en la interacción con el público y los actores invitados en cada función. El teatro La Plaza, que cuenta con un equipo de producción, le permitió dedicarse exclusivamente a ensayar la nueva versión. Entonces, Gabriel vio las obras en Zoom que estaban en temporada en ese momento para familiarizarse con el formato. Además, el propio Congreso de la República sesionaba en Zoom y esa imagen ya estaba en la retina de las y los peruanos, así que la adaptación fue orgánica. Sin embargo, subrayó que resentía la pérdida de la propuesta estética y a ello se sumaba la incertidumbre de no tener el control técnico: solo quedaba esperar que la conexión de internet del actor funcionara adecuadamente, así como la proximidad con el público.

\footnotetext{
${ }^{4}$ «Organización que trabaja por el acceso a los derechos de las personas LGTBIQ+, a través de la generación de alianzas estratégicas y la co-construcción de proyectos para nuestra comunidad» (Presente, s. f.). Su sitio web es https://presente.pe.

${ }^{5}$ «Efecto cómico rápido e inesperado en un filme o, por extensión, en otro tipo de espectáculo» (Real Academia Española y Asociación de Academias de la Lengua Española, s. f.).
} 
Como estrategia para promover la interacción con el público, se convocaba, en las redes sociales, a ocho personas que hubieran comprado su entrada y que desearan participar en la función como panelistas. Con estas personas, se realizaba una dinámica previa a la función para probar la técnica y se les daba un pequeño texto e indicaciones mínimas para la interacción con el actor. De la Cruz señala lo siguiente:

En el teatro por Zoom, pierdes el contacto con el público y la oportunidad, en la comedia, de estar acompañado por las reacciones y las risas. Esto se suplía con los invitados del público, que representaban al resto y ayudaban al actor a cerrar los momentos de la obra.

A partir de esa experiencia, Gabriel de la Cruz decidió embarcarse en una nueva obra pensada - desde el origen - como teatro virtual, retomando la línea que investiga hace muchos años, el teatro testimonial, con temática basada en el mundo gay. En el teatro testimonial, él suele trabajar con personas vinculadas con el tema que está investigando y, por ello, dichas personas no son necesariamente actores. Durante el proceso de ensayos, orienta la elaboración del testimonio y, a partir de lo que cada intérprete brinda, compone los momentos de la dramaturgia a través de acciones y movimientos en el espacio.
En medio de la pandemia, uno de los problemas más agudos es la falta de trabajo; por ello, muchos jóvenes gais recurrieron a abrirse una cuenta en OnlyFans, una red social de contenido erótico y sexual en la que el «visitante» paga una suscripción mensual de entre 15 y 30 soles para acceder a fotos y videos. En este contexto, Gabriel de la Cruz decidió investigar el mundo del trabajo sexual y de los escorts ${ }^{6}$ en Lima. Entonces, realizó la convocatoria e hizo una audición por Zoom. De la Cruz señala que uno de los participantes elegidos tenía mayor noción de cómo interpretar frente a la cámara por su práctica en la creación de videos. Dicho participante comprendía la convención y eso fue de gran utilidad. Para Gabriel fue un gran desafío dirigir a distancia las coreografías y, a la vez, cuidar el desarrollo del contenido que era íntimo. A esto se sumó la dificultad de que los intérpretes no contaran con buena conexión a internet. Por esta razón, en la última parte del montaje, y con las medidas de bioseguridad correspondientes, reunió al equipo en un hotel -los dos intérpretes, un artista audiovisual y él, como director-, tanto para ensayar como para realizar las funciones de Cholo macho. En esta experiencia, contar con un artista audiovisual le permitió componer con los movimientos de cámara. Fue un personaje más de la obra.

En ambas obras, al final de cada función, se transmitía un video con los créditos y 
luego se abría el chat para recibir comentarios del público, que eran de todo tipo. Al estar detrás de la pantalla, algunos usando sobrenombres, se sentían libres de expresar sus opiniones sin filtro, en ocasiones de manera agresiva en cuanto al lenguaje o contenido; se suplían los aplausos con los comentarios. En la obra Congrezoom, con Ernesto Pimentel, los comentarios del público se concentraban en elogiar al actor, mientras que, en la obra de teatro testimonial Cholo macho, en la que el objetivo era interpelar al espectador, el público agradecía la valentía de los intérpretes por tocar los temas del trabajo sexual y la sobrevivencia desde su experiencia personal. Para Gabriel de la Cruz, el teatro digital sí es teatro en vivo: hay personajes, vestuario, iluminación, etcétera, pero no existe la devolución por parte del público.

Con respecto al futuro, Gabriel considera que parte de lo que ha generado el teatro virtual va a quedar, más aún cuando permite tener público de diferentes partes del país y del mundo. Por ahora, no tiene un proyecto futuro de teatro en Zoom; ha adaptado su proyecto de teatro presencial a un corto documental, con el cual planea participar en el Festival de Artes Escénicas por la Diversidad en junio de 2021. Este corto audiovisual se difundirá primero como teatro digital grabado y luego hará el recorrido que suele hacer un producto como este.

En el teatro virtual, hay cosas que no se pueden controlar - afirma Gabriel-y eso coloca al artista escénico en un estado muy vulnerable como creador, porque se pierde la posibilidad de envolver al público en una experiencia. El público puede ver la obra y, al mismo tiempo, revisar su celular, enviar mensajes por WhatsApp o usar cualquier otra red; no se sabe si está prestando atención. Por ello, y hasta que se pueda volver al teatro presencial, hará productos audiovisuales y se ocupará en crear una experiencia al momento de transmitirlos al espectador.

\section{Entre lo escénico y lo instalativo}

Cuando inició el estado de emergencia por la pandemia en marzo de 2020, Diana Daf se encontraba creando Preludio, ficciones del silencio, obra con la que había ganado un fondo del Ministerio de Cultura el año anterior. Durante el confinamiento estricto, el Ministerio amplió el plazo de presentación de los proyectos audiovisuales, pero no para los de artes escénicas ${ }^{7}$. Entonces, se vio obligada a concluir con la presentación de la obra en formato digital.

Su obra era performática y empleaba material audiovisual; por eso, en un

\footnotetext{
${ }^{7}$ La Dirección General de Industrias Culturales y Artes, parte del Ministerio de Cultura, se divide en cuatro direcciones. La dirección de Artes ve lo referido a los proyectos escénicos, y la dirección del Audiovisual, la Fonografía y los Nuevos Medios se ocupa de los proyectos audiovisuales (Portal de Transparencia Estándar, 2020).
} 
momento, pensó convertirlo en un documental, pero, al conversarlo con colegas que trabajaban en el rubro de cine expandido ${ }^{8}$, decidió hacer una versión entre lo escénico y lo instalativo. Además, vio diferentes obras para estudiar los recursos que empleaban en el formato de teatro digital y cuál era -en palabras de Diana Collazos-el «lenguaje de Zoom». Le atrajo la posibilidad de jugar con la idea de trabajar con momentos performáticos y audiovisuales en una plataforma audiovisual en la que las fronteras se confunden.

La obra Preludio, ficciones del silencio trata sobre el duelo y los rituales de enterramiento. Aunque no fue creada en pandemia, resuena con el contexto de manera muy estrecha. Fue transmitida, de forma sincrónica, desde el teatro de la Universidad del Pacífico. El vacío del teatro fue parte de la escenografía. Para ingresar, la administración del teatro exigía que todo el equipo se realizara pruebas para detectar la COVID-19, y les dio dos días para ensayar y grabar. Inicialmente, este era el teatro donde se iba a estrenar la obra en el marco del Festival Sótano 2, que luego optó por hacer una versión virtual. En funciones posteriores, la obra se presentó en versión grabada y así participó en el Festival de Artes Escénicas de Lima (FAEL) en enero de 2021.
Diana Daf afirma que el lenguaje de Zoom no llega a ser ni audiovisual ni escénico. Es un espacio nuevo e híbrido, en pixeles, y se puede crear desde las condiciones que ofrece. Ahora se encuentra investigando las posibilidades del OBS (Open Broadcaster Software), que considera más versátil porque es posible hacer swicht, es decir, controlar el ingreso y la salida de la proyección de varias cámaras, tarea que debe realizar un(a) director(a) audiovisual, tal como sucede en los programas de televisión en vivo.

Diana afirma que, en las obras de teatro digital que ha podido ver, identifica que a los artistas escénicos les faltan herramientas del lenguaje audiovisual y de iluminación para poder transmitir mejor los momentos y generar diversas atmósferas en esta plataforma, incluso en las versiones grababas. En ese sentido, es necesario componer un ritmo de «edición en vivo» para el teatro virtual, porque es común ver a un personaje hablando por tiempo prolongado frente a la cámara en un plano cerrado, y muchas veces esto no es parte del tratamiento de la propuesta, sino que ocurre por falta de exploración. Esto también da cuenta del poco acceso a tecnologías mínimas, a las condiciones de conectividad, al tipo de cámara o dispositivo con el que se cuenta. Más que equipos sofisticados, se necesita saber qué se puede hacer con ellos, afirma.

${ }^{8}$ Cine expandido «se refiere a un campo del arte en que los creadores procuran ampliar los términos y las condiciones de las cintas mostradas al espectador, sumándole a esto un interés por crear una experiencia viva en la audiencia más que una lectura convencional del metraje precorregido» (Cinencuentro, 2007, párr. 3). 
En cuanto a la relación con el público, ha probado realizar la función con el chat activado durante esta y también después. El proyecto inicial proponía hacer presentaciones en colegios de Huaraz, lugar de referencia de la obra, uno de ellos ubicado en el distrito de Masin en Áncash, pero no se logró hacer la transmisión porque no contaban con conexión a internet. Entonces, realizó funciones en otros dos colegios, con estudiantes en el último año de secundaria de dos colegios en Huaraz -alrededor de 170 adolescentes-, quienes se compenetraron con el tema de la obra. En el diálogo posterior a la función, por ejemplo, comentaron sobre la importancia de conocer la historia de sus abuelos. Diana Daf comenta que los adolescentes están más acostumbrados a la exposición de imágenes y tienen más familiaridad con lo audiovisual. Su ojo interpretativo - sostiene- permite que acepten y entiendan los códigos.

Preludio, ficciones del silencio seguirá un camino más común en el medio audiovisual: la difusión en festivales. Diana Daf está dispuesta a difundir su obra en diferentes espacios, incluso de manera gratuita. Para ella, aún está pendiente el estreno de la obra en versión presencial con público. La obra ha significado para Diana Daf ampliar también sus conocimientos audiovisuales. Ella tiene experiencia en dirección' ${ }^{9}$, pero, en cuanto a edición, solo la hacía en formatos cortos; en Preludio, ficciones del silencio, fue ella quien editó la obra de una hora de duración y lo hizo de manera tal que no fuera solo la grabación de la obra, sino que tuviera un código diferente, híbrido.

Sobre los proyectos a futuro, tiene uno audiovisual y otro de teatro en Zoom. Por otro lado, Diana Daf también es parte del grupo humano que gestiona el espacio escénico Elgalpon.espacio ${ }^{10}$, que ha logrado mantenerse gracias al apoyo que recibieron por parte del Ministerio de Cultura. El equipo ha ido a un ritmo más pausado en la reconfiguración de la planificación anual mientras buscan capacitarse en el manejo de herramientas tecnológicas.

\section{Resultados económicos}

En la experiencia de Carol Hernández con respecto a la parte económica, la rentabilidad fue más grande al inicio de la cuarentena estricta, cuando las personas recién estaban adaptándose al encierro y estaban ávidas de ver propuestas; luego, esto bajó, cuando las restricciones se flexibilizaron. En ningún caso el margen fue muy amplio. La modalidad de pago era vía PayPal, y entre los actores se repartían las tareas de administración, venta de entradas y contabilidad; era como tener una

\footnotetext{
${ }^{9}$ Diana Daf dirigió, junto con Jean Alcocer, el documental El círculo de tiza, que trata sobre la vida del fundador del teatro callejero en el Perú, Jorge Acuña Paredes.

${ }^{10}$ «Asociación Cultural autogestionaria e independiente formada por creadores y especialistas de diferentes áreas del arte y la cultura» (Elgalpon.espacio, s. f., párr. 1).
} 
boletería en cada país. Carol Hernández comenta que abrió la cuenta en PayPal en el primer mes de la pandemia y, poco después, basada en su formación como publicista, reconoció la necesidad de crear una página web, de generar contenidos frecuentes en redes sociales y, en general, de trabajar con profundidad el promover su marca personal en el mundo digital. Ella sostiene que la autogestión es una realidad que salvará a los artistas; aunque no siempre haya rédito económico, de esa manera no se frenaría la posibilidad de crear.

Para Gabriel de la Cruz, en términos económicos, la campaña del teatro La Plaza funcionó bien y esos ingresos le permitieron recuperar la inversión del proyecto anterior, que quedó trunco. En oposición, los ingresos económicos de la obra Cholo macho no fueron buenos, porque la temporada fue en noviembre, mes en que las restricciones sanitarias se habían flexibilizado y había convulsión política en el país. Asimismo, Gabriel considera que es posible que el público se haya cansado de ver teatro por Zoom, de tolerar los problemas técnicos como que la obra se entrecortara por la conexión a internet de la producción o del propio espectador. Afirma que el público fue permisivo al inicio de la pandemia con respecto a los límites técnicos y en pro de dar oportunidad al teatro, pero que luego se saturó; entonces, prefirió consumir Netflix. La temporada se cortó cientes para pagar a los intérpretes. Señala De la Cruz:

En el teatro, uno controla lo que el público va a mirar: le das color; creas la estética. Pero, cuando estás en tu casa con una cámara, el espectador ve a través de un objeto que es un intermediario entre el espectador y el público; por ello, el encargado de manejar ese [canal] intermediario, sea computadora o celular, debería ser un artista audiovisual.

En el caso de Diana Daf, la obra Preludio, ficciones del silencio ha participado en dos eventos: Festival Sótano 2, edición virtual, del Centro Cultural de la Universidad del Pacífico, entre septiembre de 2020 y febrero de 2021; y el FAEL, en enero de 2021, también en edición virtual y organizado por un grupo de centros culturales. Los organizadores de ambos festivales asumieron la difusión y la venta de entradas. Además, Diana Collazos también realizó funciones independientes autogestionadas. El resultado, en ambos eventos, fue similar: la venta de entradas fue escasa y, en general, Diana considera que la gente no tiene voluntad de pagar para ver teatro digital. La crisis sanitaria ha generado también una crisis económica y de salud mental, a lo cual se suma la crisis política y la campaña electoral en pleno año del bicentenario de la Independencia del Perú. Dentro de ese panorama, si alguien decide comprar una entrada -sostiene-, buscará una que le asegure 
que será de su agrado. Por ello, se vuelve más complejo aún vender entradas de obras con propuestas menos conocidas.

\section{Conclusiones}

El teatro peruano estaba en crisis antes de la pandemia por falta de políticas culturales, lo que generaba un mínimo apoyo estatal y privado. También hay pocas salas teatrales y estas están concentradas en algunos distritos de Lima y algunas otras ciudades del Perú. Existe centralismo en la formación de artistas escénicos: solo hay cuatro centros de formación profesional en Lima y uno en Trujillo. Estas circunstancias grafican un medio semiprofesional. Durante la pandemia, el teatro digital transmitido en vivo, principalmente por Zoom, apareció como alternativa; luego, también se empleó el teatro grabado, editado y retransmitido.

El teatro ha tenido siempre una resonancia con el devenir social, político, filosófico e, incluso, tecnológico. A lo largo de la historia, ha incorporado diversos avances a sus códigos de significancia; de hecho, antes de la pandemia, ya existían trabajos que incluían el lenguaje multimedia dentro de la narrativa escénica. El término teatro digital se usa desde 1995 aproximadamente, y se refiere a diferentes experiencias híbridas entre el lenguaje escénico y el audiovisual, con público presencial y virtual. Jorge Dubatti, en el año 2015, afirmó que el tecnovivio no sustituye de manera alguna al convivio.
El contexto ha abierto el espacio para adaptarse y familiarizarse con el tecnovivio, como se puede apreciar en prácticas como el after, en que, después de las funciones, el equipo creativo conversa con el público, algo que ocurría pocas veces en el teatro presencial, es decir, como teatro foro. El uso del chat es una alternativa para que el público reaccione casi en simultáneo, pero dependerá de las características de la obra; además, es necesario considerar que algunas participaciones pueden ser agresivas, como suele suceder en las redes sociales. Las reacciones son emocionales y la acción de escribir o poner un emoticón dispersa al espectador.

Este tiempo de pausa del teatro presencial ha permitido problematizar el hecho escénico, revisar sus fundamentos y revalorar su importancia en la sociedad.

Para Carol Hernández, el teatro digital le dio una nueva dimensión de intimidad a la creación en impro testimonial, ya que, como elemento adicional, los intérpretes se encontraban en sus casas y con las personas con las que convivían. También, encontró una estética funcional para el teatro testimonial en Zoom y para ello se capacitó en lenguaje audiovisual.

En la experiencia de Gabriel de la Cruz, el teatro digital es un lenguaje híbrido; por ello, contar con un artista audiovisual es necesario. Afirma que en este formato se pierden las posibilidades estéticas del lenguaje escénico y se pierde también 
el control de lo que puede llegar a ver el público según la conexión con la que se cuente. Por estas razones, en la obra Cholo macho conservó el convivio, al menos entre los intérpretes, reuniéndolos en un mismo espacio, desde donde transmitió la obra. Señala, además, que no se puede cuidar la relación con el público, el cual, desde su computadora o celular, puede hacer otras tareas. En la comedia Congrezoom, para paliar esa situación, un grupo pequeño de público participaba con la cámara y el micrófono prendidos, con la intención de intentar representar al total de los espectadores.

Diana Daf viene del mundo escénico y el audiovisual, así que asumir la realización de su proyecto performático, que incluía piezas audiovisuales, la acercó a explorar las posibilidades del teatro digital y el cine expandido.

Para ella es necesario que los artistas escénicos que quieran hacer teatro digital incorporen herramientas audiovisuales, tanto en el lenguaje como con el uso de tecnologías y dispositivos. Por ejemplo, si el teatro digital es transmitido en streaming directo, se debe incluir la participación de un(a) director(a) de cámaras o switch que orqueste los momentos y atienda las incidencias.

Sobre la base de la información recabada, se puede afirmar que el teatro digital tiene condiciones para democratizar el que- difusión y acceso a la programación. La reducción de costos y el prescindir de una sala permitieron que gente más joven produjera y que haya más cantidad de producciones que llegaron a estrenarse. Además, los actores mayores y menos familiarizados con la tecnología han podido actuar gracias a la convocatoria y guía de los más jóvenes. El teatro digital ha permitido acceder a un público más amplio que proviene de diferentes distritos de Lima, de diversas regiones del Perú y del exterior. Asimismo, ha atraído a espectadores de diversas edades e, incluso, a un nuevo público que no asistía al teatro presencial, ya sea por el costo de las entradas, por la lejanía de las pocas salas de teatro existentes o por falta de oferta cultural en su ciudad. También ha sido una alternativa para personas que se sienten más cómodas viendo obras mediadas por la tecnología.

Las duraciones, los horarios y el número de funciones de las temporadas en el teatro digital tienen otra dinámica: son más cortas y funcionan en horarios diversos, a diferencia de lo que ocurre en el teatro presencial.

Por otro lado, el público joven está más familiarizado con la interpretación del lenguaje audiovisual y es posible que por esa razón tenga mejor disposición al lenguaje híbrido.

En contraste, solo pueden acceder al teatro digital los espectadores que cuentan 
con conexión a internet y que pueden manejar mínimamente la plataforma desde donde se transmite. Se depende de la condición de la conexión a la red de los artistas y el público para conservar la calidad del producto artístico y su experiencia. Este tipo de teatro limita la interacción con el público. Al ser un lenguaje híbrido y mediado por la tecnología, deben manejarse herramientas del lenguaje audiovisual, con las que los artistas escénicos habitualmente no cuentan. Estos hallazgos han ocurrido probando en el camino, lo que ha traído una inversión de tiempo para investigar, además de un costo personal y emocional alto para los artistas escénicos.

Los cambios continuos de medidas para el manejo nacional de la pandemia afectan el consumo de teatro digital. Adicionalmente, las condiciones de la pandemia hacen que las personas se agoten de toda actividad mediada por el soporte virtual: teletrabajo, vida social, entretenimiento, telesalud, etcétera. A ello se suma, en el Perú, la crisis política, la polarización social por las elecciones presidenciales, y el agotamiento emocional y económico.

Frente a lo que ha significado esta experiencia, es probable que, en el futuro, el teatro presencial se mezcle con el audiovisual de manera más frecuente y diversa, por ejemplo, con la idea de que parte del elenco se encuentre en un lugar físico diferente.
El teatro digital y el tecnovivio seguirán su propio discurso y se afianzarán como formato de creación híbrida.

Al cierre de este artículo, el mundo avanza de manera desigual con la vacunación; los países más ricos cuentan con más vacunas y hay otros a los que todavía no llegan. Se calcula que la vacunación culminará en el año 2022 y que, aun después de eso, se debe aprender a convivir con el coronavirus. Los países que retornen antes a una convivencia similar a la prepandémica darán la pauta de lo que seguirá para el teatro. 
Antón, J. (1995, 14 de noviembre). La Fura y el grupo Brith Gof muestran en Barcelona un trabajo conjunto. El País. https:/elpais.com/diario/1995/11/15/ cultura/816390011 850215.html

Cañas-Restrepo, M. Á. (2005). Acercamiento a la investigación sobre el espectáculo en las relaciones estética-tecnología. Tecno Lógicas, (14), 128-159. https:// doi.org/10.22430/22565337.539

Cinencuentro. (2007, 22 de enero). Cine expandido: la transgresión en pantalla. https://www.cinencuentro. com/2007/01/22/cine-expandido-la-transgresion-en-pantalla/

Cubas, F. (2020, 3 de noviembre). «Esto no es teatro»: la polémica por las obras virtuales. El Foco. https://elfoco.pe/ informes/copia-de-esto-no-es-teatro-la-polemica-por-las-obras-virtuales-que-inicio-con-la-pandemia/

D’Andraia, A. (2019, 9 de enero). Mirta Romay, creadora de Teatrix: «Espero estar a la altura de lo que hizo mi viejo». Infobae. https://www.infobae.com/parati/news/2019/01/og/mirta-romaycreadora-de-teatrix-espero-estar-ala-altura-de-lo-que-hizo-mi-viejo/

Decreto de Urgencia $\mathrm{N}^{\circ}$ 058-2020 [Presidencia de la República]. (2020, 21 de mayo). Aprueban mecanismos de amortiguamiento para mitigar los efectos económicos en el sector cultura producidos en el contexto de la emergencia sanitaria por el covid-19. Diario Oficial El Peruano. https://busquedas.elperuano.pe/ normaslegales/aprueban-mecanismos-de-amortiguamiento-para-mitigar-los-efec-decreto-de-urgencia-n-058-2020-1866605-1/
Denegri, P. (2020, 31 de mayo). "Junta extraordinaria»: La obra virtual que reúne a Gisela Ponce de León y Christian Ysla. Perú21. https:// peru21.pe/cultura/junta-extraordinaria-la-obra-virtual-que-reune-a-gisela-ponce-de-leon-y-christian-ysla-teatro-cultura-noticia/

Dubatti, J. (2011). Introducción a los Estudios Teatrales. Libros de Godot.

Dubatti, J. (2015). Convivio y tecnovivio: el teatro entre infancia y babelismo. Revista Colombiana de las Artes Escénicas, 9, 44-54. http://artescenicas. ucaldas.edu.co/downloads/artesescenicas9 5.pdf

Dubatti, J. (2016). Teatro-matriz y teatro liminal: la liminalidad constitutiva del acontecimiento teatral. Cena, (19). https://doi.org/10.22456/22363254.65486

Elgalpon.espacio. (s. f.). Sobre el proyecto. https://elgalpon.espacio.pe/sobre-el-proyecto/

Gran Teatro Nacional. (2019, 16 de agosto). Grupo de arte Íntegro celebra 35 años con el estreno de "Jardín de Oro» en el Gran Teatro Nacional. https:// granteatronacional.pe/noticia/grupo-de-arte-integro-celebra-35-anoscon-el-estreno-de-jardin-de-oro-enel-gran-teatro

Japa Rojas, J. A. (2020, 26 de mayo). «Fantasma», obra de teatro online de Mariana de Althaus. La Mula. https://poramoralarte.lamula.pe/2020/05/26/ fantasma-obra-de-teatro-online-de-mariana-de-althaus/poramoralarte/ 
Jóvenes actores presentarán obra de teatro virtual desde Trujillo. (2021, 11 de marzo). Correo. https://diariocorreo.pe/edicion/la-libertad/ la-libertad-jovenes-actores-presentaran-obra-de-teatro-virtual-desde-trujillo-noticia/?ref=dcr

La Fura dels Baus. (2000, 1 de mayo). ØBS. https://lafura.com/obras/obs/

Ley, P. (1997, 8 de agosto). Teatro digital. El País. https://elpais. com/diario/1997/o8/og/cultu$\underline{\mathrm{ra} / 871077605 \text { 850215.html }}$

López Pellisa, T. (2013). La pantalla en escena: ¿es teatro el ciberteatro? Revista Letral, (11), 23-39.

Marques, A. C. (2013, 5 de enero). Manifesto Binário, La Fura dels Baus. Pcd de acm. https://anacmarquespdc.blogspot.com $/ 2013 / 01 / m a n i f e s t o-b i n a-$ rio-la-fura-dels-baus.html

Minafro Spinelli, M. (2015). La virtualidad en el teatro. TRP 21, (2), 122-135. https:// trp21.files.wordpress.com/2015/11/ trp21-n23.pdf

Portal de Transparencia Estándar. (2020). Anexo $N^{\circ}$ o1 - Organigrama del Ministerio de Cultura. http://transparencia. cultura.gob.pe/sites/default/files/ transparencia/2020/06/organigra$\underline{\text { ma/organigramafinal o.pdf }}$

Presente. (s. f.). Quiénes somos. https://presente.pe/quienes-somos/

RASL DASL Bs As. (2021, 29 de abril). PODCAST RASL DASL // 1X05 Teatro Digital (Mirta Romay) - PARTE 1 [Video]. YouTube. https://www.youtube.com/ watch?v=j8qTOy5lSOY
Real Academia Española y Asociación de Academias de la Lengua Española. (s. f.). Gag. En Diccionario de la lengua española. Recuperado el 27 de abril de 2021 de https://dle.rae.es/gag?m=form

Rebata Delgado, S. (2020). Identidad artística: desafíos pedagógicos del profesional que enseña artes escénicas en la UPC [Tesis inédita de maestría]. Universidad Andrés Bello.

Rebata Delgado, S. (2021). SEGUIR CREANDO: casos de artistas escénicas creando durante el confinamiento estricto por la crisis del Covid-19 en Lima. En G. G. Heil Vázquez, J. M. Silva y K. Janz Woitowicz (Eds.), Vivências de mulheres no tempo e espaço da pandemia de Covid-19. Perspectivas transnacionais (pp. 253-271). Editora CRV.

Rodríguez, E. (2020, 22 de diciembre). Teatro peruano: los nuevos escenarios que nos dejará la pandemia. Somos Periodismo. https://somosperiodismo.com/la-funcion-debe-continuar-los-nuevos-escenarios-del-teatro-independiente/

Vidales, R. (2020, 12 de mayo). La Fura dels Baus, pioneros del teatro digital (sin saberlo). El País. https://elpais.com/cultura/2020/05/12/babelia/1589301705 192200.html

Tmt comunica. (2018, 1 de noviembre). Mirta Romay en TMT Conversaciones [Video]. YouTube. https://www.youtube.com/watch?v=KD8sKT7d-Ws 
Villalobos Herrera, Á. (2017). Teatro y performance: (Des)encuentros. Investigación Teatral, 6-7(10-11), 51-68. https://investigacionteatral.uv.mx/ index.php/investigacionteatral/article/view/2534/4416

Zucchi, M. (2021, 3 de abril). Mirta Romay, la hija del Zar, la empresaria prolífica de la pandemia. Clarín. https://www. clarin.com/espectaculos/teatro/hija-zar-empresaria-prolifica-pandemia o jpoJQ8UKB.html 